
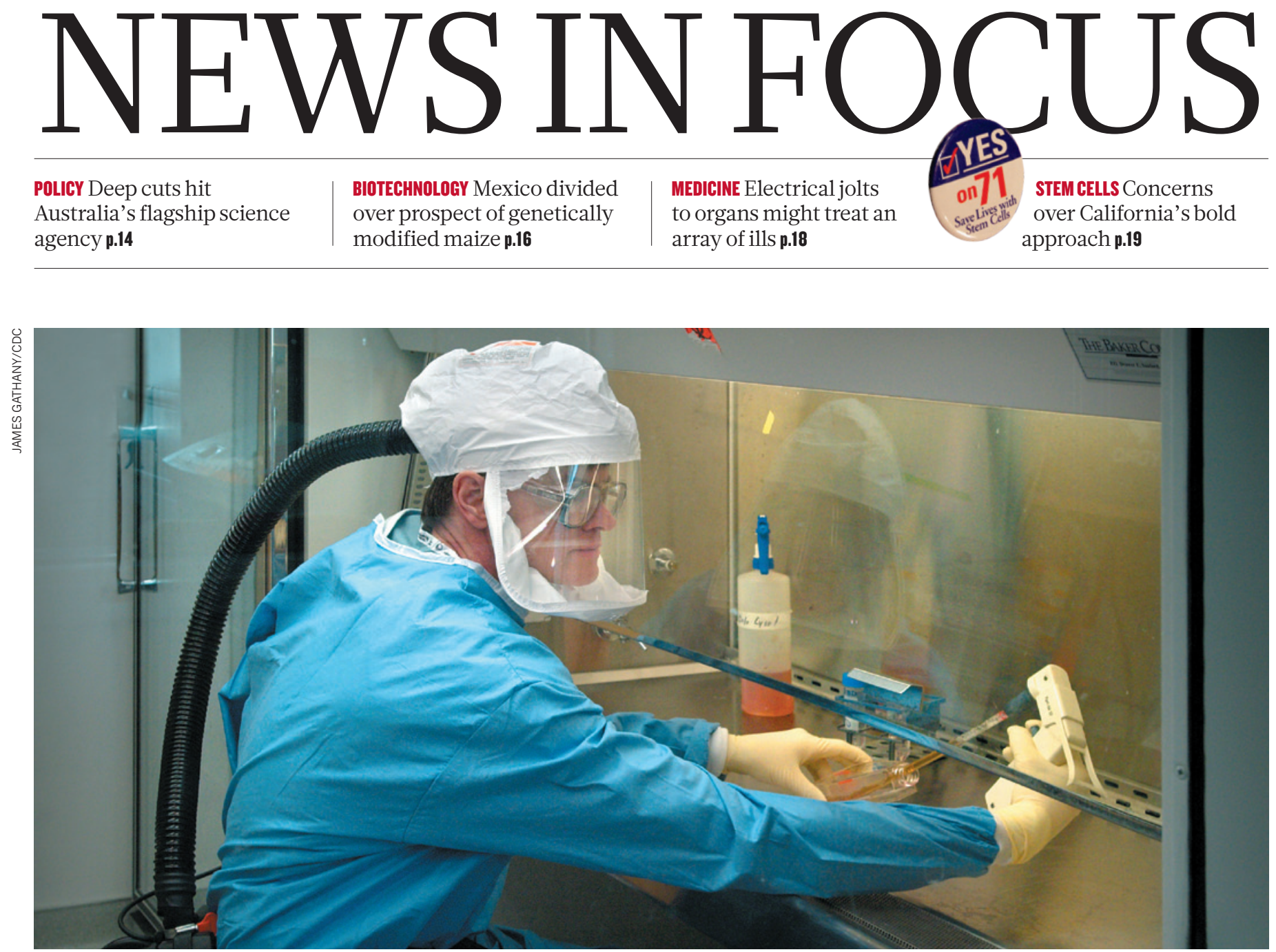

Work with potentially lethal viruses has to be done in stringent biosafety conditions.

\title{
BIOSECURITY
}

\section{Risks of flu work underrated}

\section{US funding agency disagreed with university's assessment of potential threats.}

\section{BY DECLAN BUTLER AND BRENDAN MAHER}

A controversial influenza study was run in accordance with new US biosecurity rules only after the US National Institute of Allergy and Infectious Diseases (NIAID) disagreed with the university's assessments, Nature has learned. While some biosecurity experts express shock that the work could initially have been deemed exempt, others say that the case shows that the system's checks and balances are working.

The University of Wisconsin-Madison initially ruled that the project did not fit the criteria for dual use research of concern (DURC); which includes research that could be misused to threaten public health, national security or crops or livestock. But the NIAID disagreed.

The project, led by virologist Yoshihiro
Kawaoka, is an example of 'gain-of-function' flu research, in which influenza viruses are engineered to alter properties such as the range of hosts, transmissibility and virulence. Such research is controversial because it could be used to generate flu strains with pandemic potential. The study aimed to establish the likelihood of a 1918-like pandemic virus emerging from current avian strains, and to investigate what made the $1918 \mathrm{H} 1 \mathrm{~N} 1$ virus - which killed some 40 million people - so virulent.

The team used genes from wild avian $\mathrm{H} 1 \mathrm{~N} 1$ viruses that coded for proteins resembling those of the 1918 virus to construct new viruses. The new viruses were not only able to spread between ferrets - the best current model for human flu transmission - they were also more virulent than the original avian viruses. The team therefore argues that there is a high risk that a 1918-like virus could emerge naturally ${ }^{1}$.

The NIAID has funded the six-year project since 2009. But when government introduced the new rules in March 2012, the agency asked the university to check whether the project fell under these regulations.

Research falls under the DURC rules if it meets any of seven criteria; for example, if it increases the stability or transmissibility of the agent or toxin (see go.nature.com/pwryge). But when the university reviewed the proposal in July 2012 and the progress report the following November, it concluded that the project did not meet any of the criteria. It argued that the research would not add risk beyond that done to reconstruct the 1918 flu virus in 2005 - nor would it generate more virulent viruses.

But in a letter to the university on 26 February 2013, Carole Heilman, director of the 
- NIAID's Division of Microbiology and Infectious Diseases, says that the agency "respectfully disagrees" with these assessments. "This is the final determination," she wrote, instructing the university to develop the required risk-mitigation plan. That plan was approved in April 2013.

Nature obtained the review by the biosafety committee and the risk-benefit assessment of the university and sent them to biosafety and biosecurity experts. Richard Ebright, a molecular biologist at Rutgers, The State University of New Jersey in Piscataway, says that the research "unequivocally" met four of the seven DURC criteria. And David Relman, a member of the board that drafted the criteria and a microbiologist at Stanford University in California, says that he was surprised that the project was not initially seen as DURC, calling it a "poster child" for such research.

But Adolfo Garcia-Sastre, director of the Global Health and Emerging Pathogens Institute at Mount Sinai Hospital in New York is reassured by the process. "If anything, this means that the system is working," he says. "There are a lot of double- and triple-checks being conducted before experiments are approved, and this has been the case for these experiments."

The DURC regulations were introduced after groups led by Kawaoka and Ron Fouchier of the Erasmus Medical Center in Rotterdam, the Netherlands, managed to engineer potentially pandemic forms of the H5N1 avian flu virus ${ }^{2,3}$.

Rebecca Moritz, a programme manager at the University of Wisconsin-Madison's Office of Biological Safety, says that the university had long discussed DURC issues, but had no official framework in place to assess such work, and had to put together an evaluation process at short notice after the government's rules were released.

The biosafety committee's rationale, she explains, was to compare the risks of the proposed project with those of research involving the reconstruction of the 1918 human flu virus $^{2}$, which had already been approved. The committee felt the new work did not pose additional risks, she says. But the committee's thinking shifted after the NIAID emphasized that the work could generate riskier versions of current bird viruses, she says.

Experts are strongly divided over the risks and benefits of gain-of-function flu research. Relman opposes such research, but says that whatever stance scientists take, everyone should agree that the process for assessing it is transparent and effective.

Oversight cannot be left to scientific agencies with an inherent interest in promoting science, he says. "What is needed is dispassionate, nonpartisan rigorous oversight of this work".

\footnotetext{
1. Watanabe, T. et al. Cell Host Microbe 15, 692-705 (2014)

2. Imai, M. et al. Nature 486, 420-428 (2012)
}

3. Herfst, S. et al. Science 336, 1534-1541 (2012).

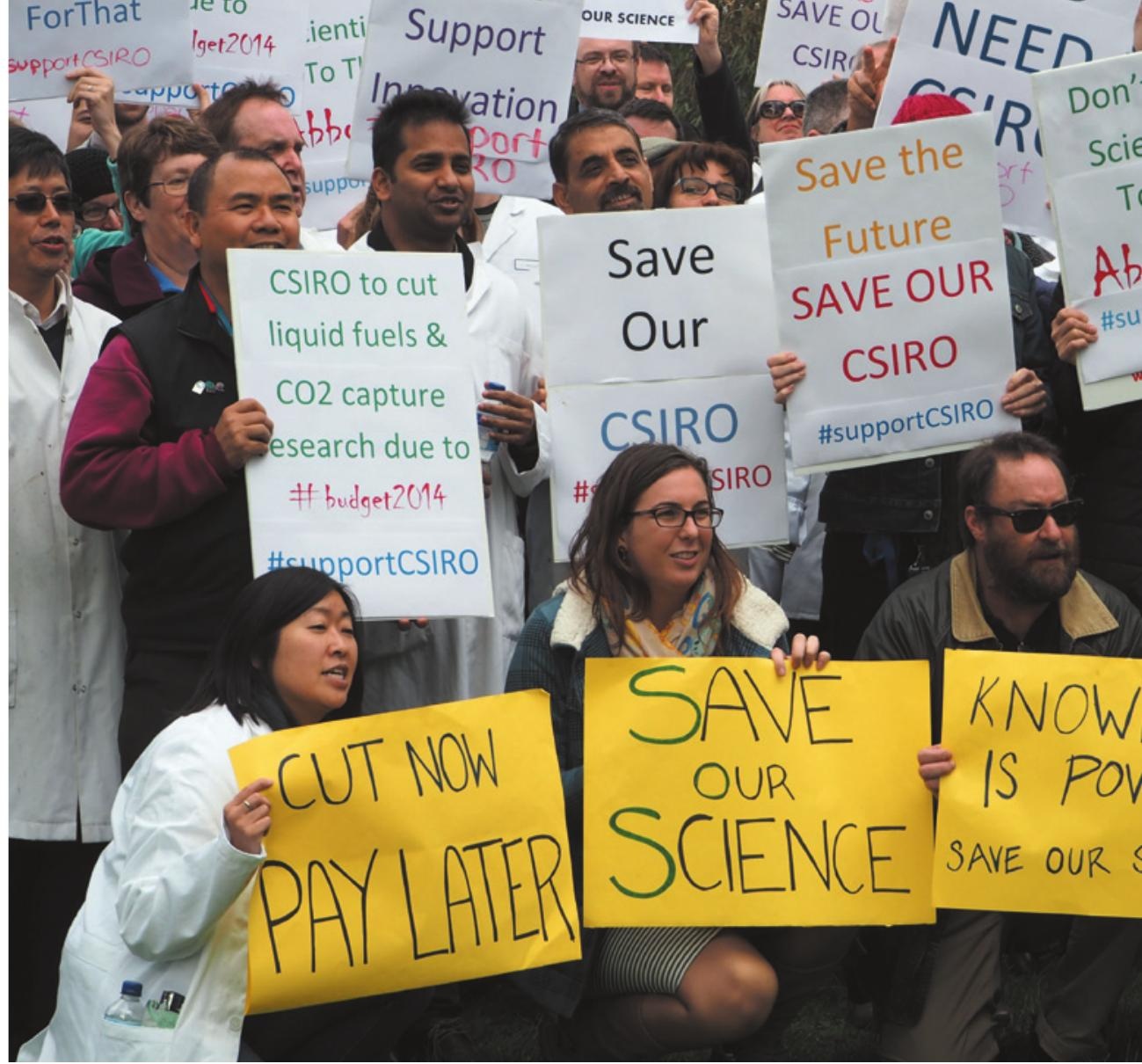

Staff from the Commonwealth Scientific and Industrial Research Organisation facility in Hobart, Australia, demonstrated on 26 June over funding cuts.

POLICY

Australian budget
hits science jobs

Research-agency staff protest over slashed spending and concerns about country's future research capability.

\section{BY LEIGH DAYTON}

$\int$ oining together in vociferous chants of defiance, nearly a thousand scientists at Australia's premier science agency protested across the country last week as it began to shed jobs in response to deep funding cuts.

The measures, announced in May's budget, include a $16 \%$ cut in funds - a reduction of Aus $\$ 115$ million (US\$108 million) - for the Commonwealth Scientific and Industrial Research Organisation (CSIRO) over the next four years. The budget, which is pending passage by the Australian Senate, also includes closures and slashed funds at other scientific organizations. The move is one in a series of steps enacted by the new government, elected last September, that have heavily targeted climate and environmental science.
The CSIRO must now decide where the budget cuts will fall. But heads of divisions from radio science to agriculture and health — are struggling to make the required cuts while safeguarding core priorities. The first of its employees to go are 28 researchers and 3 support staff at the organization's Marine and Atmospheric Research division in Hobart and Aspendale.

The losses underscore concerns in the scientific community that the government does not support environmental and climate science. Michael Borgas, an air-quality scientist and acting secretary for the CSIRO's staff association, says that one budget measure specifically targets climate science. It includes an Aus $\$ 20$-million cut, about 69\%, to the Australian Climate Change Science Program, of which the CSIRO was a major beneficiary. "Since the budget, there's been real fear for the 